\title{
An optical study of multiple NEIAL events driven by low energy electron precipitation
}

\author{
J. M. Sullivan ${ }^{1}$, M. Lockwood ${ }^{1,2}$, B. S. Lanchester ${ }^{1}$, E. P. Kontar ${ }^{3}$, N. Ivchenko ${ }^{4}$, H. Dahlgren ${ }^{4}$, and D. K. Whiter ${ }^{1}$ \\ ${ }^{1}$ School of Physics and Astronomy, University of Southampton, UK \\ ${ }^{2}$ Rutherford Appleton Laboratory, Didcot, Oxfordshire, UK \\ ${ }^{3}$ Department of Physics and Astronomy, University of Glasgow, UK \\ ${ }^{4}$ Space and Plasma Physics, School of Electrical Engineering, KTH, Stockholm, Sweden
}

Received: 8 January 2008 - Revised: 14 May 2008 - Accepted: 6 July 2008 - Published: 11 August 2008

\begin{abstract}
Optical data are compared with EISCAT radar observations of multiple Naturally Enhanced Ion-Acoustic Line (NEIAL) events in the dayside cusp. This study uses narrow field of view cameras to observe small-scale, short-lived auroral features. Using multiple-wavelength optical observations, a direct link between NEIAL occurrences and low energy (about $100 \mathrm{eV}$ ) optical emissions is shown. This is consistent with the Langmuir wave decay interpretation of NEIALs being driven by streams of low-energy electrons. Modelling work connected with this study shows that, for the measured ionospheric conditions and precipitation characteristics, growth of unstable Langmuir (electron plasma) waves can occur, which decay into ion-acoustic wave modes. The link with low energy optical emissions shown here, will enable future studies of the shape, extent, lifetime, grouping and motions of NEIALs.
\end{abstract}

Keywords. Ionosphere (Auroral ionosphere, Plasma waves and instabilities) - Space plasma physics (Wave-wave interactions)

\section{Introduction}

Naturally Enhanced Ion-Acoustic Lines (NEIALs) have been seen in Incoherent Scatter Radar (ISR) data for almost 20 years, as an increase in received power of up to 3 orders of magnitude above the normal thermal level. NEIALs have been observed in the night-side ionosphere using the Millstone Hill radar (Foster et al., 1988) and mainland EISCAT radars at Troms $\varnothing$ (Collis et al., 1991; Rietveld et al., 1991, 1996), and more recently in the dayside cusp region using

Correspondence to: J. M. Sullivan

(jms@phys.soton.ac.uk) the EISCAT Svalbard Radar (ESR) (Buchert et al., 1999; Grydeland et al., 2003; Ogawa et al., 2006). This paper is based on the latter class of NEIALs, occurring in the dayside ionosphere. Interferometry studies at Svalbard, using multiple receivers to resolve features within the main radar beam, have shown that the structures responsible for these enhancements can be of the order of $100 \mathrm{~m}$ across, i.e. much smaller than the radar beam width. This implies that the scattering cross section must be increased by up to 5 orders of magnitude to explain NEIAL observations (Grydeland et al., 2003). For a review summarising the observations of NEIALs from various sites, and the proposed theories to explain them, see Sedgemore-Schulthess and St.-Maurice (2001).

Combined radar and optical studies of these filamentary enhancements have identified a link between NEIALs occurring in the dayside cusp and thin rayed auroral structure of similar scale size (Blixt et al., 2005; Grydeland et al., 2004). Recent spectrographic imaging studies have shown that rayed aurora is associated with precipitating auroral electrons of mixed energy, with a large contribution from low energy electrons (Ivchenko et al., 2005; Dahlgren et al., 2008a).

From a number of proposed theories, "parametric decay" has emerged in recent studies as the most likely candidate for the mechanism responsible for NEIAL observations in the dayside cusp. In this interpretation, low energy electron beams cause the growth of unstable Langmuir (electronplasma) waves through the bump-on-tail instability; these waves decay to ion-acoustic wave modes at ISR wavelengths (Forme, 1993, 1999; Kontar and Pécseli, 2005). Enhanced Langmuir waves accompanying NEIAL signatures have been observed in previous studies, both in the nightside ionosphere using the EISCAT UHF and VHF receivers at Tromso (Rietveld et al., 2002), and on the dayside using the EISCAT Svalbard Radar (Strømme et al., 2005). The requirement

Published by Copernicus Publications on behalf of the European Geosciences Union. 
of the parametric decay mechanism for low energy electron beams can account for the observed link with rayed aurora, now known to contain a significant population of low energy electrons.

Theoretical models of parametric decay, although able to explain general features of observations, cannot yet reproduce the behaviour of NEIALs in the dayside cusp entirely. NEIAL occurrences can also sometimes be explained in terms of ion-streaming instabilities (Wahlund et al., 1992), but density requirements are often prohibitively high to match observations in the cusp. However, observations of NEIALs in the night-side ionosphere show behaviour more consistent with a current driven (i.e. ion-electron streaming instability) interpretation, especially with enhancements occurring at low altitudes $(<250 \mathrm{~km})$. There are also indications that night-side NEIALs are often seen near the edges of structured auroral arcs, as opposed to within filamentary rays (Collis et al., 1991; Michell, 2007). This suggests the possibility that dayside and nightside echoes may be the result of differing generation processes, but with similar signatures in the radars.

Previous optical camera studies of dayside NEIALs have used imaging either with a long-pass cut-off filter applied or in white light, and concentrated on the prompt $\mathrm{N}_{2}$ (1st positive band at 670 to $750 \mathrm{~nm})$ and $\mathrm{N}_{2}^{+}(1 \mathrm{st}$ negative bands at 427.8 and $470.9 \mathrm{~nm}$ ) emissions. The low-energy component of auroral precipitation can be imaged using the forbidden oxygen (OII) ${ }^{2} \mathrm{P}-2 \mathrm{D}$ emission at 732 and $733 \mathrm{~nm}$, which is predominantly produced by auroral electrons with energies of around $100 \mathrm{eV}$.

Few studies have compared auroral emissions present within the radar beam with the occurrence of NEIALs. Where attempts have been made to quantify different emissions, the parallax effects of using instruments at locations separated from the radar have not been taken into account. Geometry considerations become very important at the small-scale level needed to study NEIAL behaviour. This is discussed further in Sect. 3.1.1 of the present paper.

Previous studies have suggested that high-energy particles may also have an important part to play in the generation of NEIALs (Lunde et al., 2007). It may be possible to differentiate between different NEIAL generation mechanisms by determining whether the presence of high-energy precipitation directly drives the instability itself or provides more favourable conditions for NEIALs to be observed at ISR wavelengths.

In this paper, the relationship between multiple NEIAL events and incoming particle precipitation energies is studied in detail, using simultaneous auroral imaging at different wavelengths. In addition data from a Defence Meteorological Satellite Program (DMSP) satellite pass at approximately $800 \mathrm{~km}$ altitude is combined with Langmuir wave modelling. The average altitude for NEIAL generation was found to be around $700 \mathrm{~km}$ in this study. The DMSP data therefore greatly enhances our ability to investigate directly driving conditions at NEIAL altitudes, as well as using signatures from optical measurements up to $300 \mathrm{~km}$ in altitude.

\section{Ground-based instrument details}

\subsection{EISCAT Svalbard Radar (ESR)}

The ESR is an incoherent scatter radar facility, using one $42 \mathrm{~m}$ antenna, fixed in the field-aligned direction of $181.0^{\circ}$ in azimuth and $81.6^{\circ}$ in elevation, and one steerable $32 \mathrm{~m}$ antenna. The location, just outside Longyearbyen at $78^{\circ} 9^{\prime} \mathrm{N}$, $16^{\circ} 2^{\prime} \mathrm{E}$, on the Norwegian island of Spitsbergen, means it is ideally situated to study dayside cusp phenomena. For the period of interest studied here the radar programme "tau0" was used, an alternating code experiment covering all altitudes from $120 \mathrm{~km}$ to $1200 \mathrm{~km}$. Data were recorded from the $32 \mathrm{~m}$ and $42 \mathrm{~m}$ dishes alternately. At the time of the observations presented, the $32 \mathrm{~m}$ antenna was deployed at a low elevation and therefore only the $42 \mathrm{~m}$ measurements are used here. The integration time is $6.4 \mathrm{~s}$ but followed by a gap of $6.4 \mathrm{~s}$ for each data point.

\subsection{Optical instrumentation}

The Spectrographic Imaging Facility (SIF) was in operation at the Auroral Station in Adventdalen at $78^{\circ} 12^{\prime} \mathrm{N}, 15^{\circ} 50^{\prime} \mathrm{E}$, i.e. approximately $7 \mathrm{~km}$ north-west of the ESR. The University of Southampton and University College London instrument platform consists of a narrow field auroral imager and a High Throughput Imaging Echelle Spectrograph (HiTIES). Supporting photometers with interchangeable filters are also available.

The Andor imager was provided by Andor Inc. on loan for January 2004. It was used as a test camera in the feasibility study for the Auroral Structure and Kinetics (ASK) project (Ivchenko et al., $2008^{1}$ ), run jointly by the University of Southampton and KTH, Stockholm. The lack of full thermal control for the testing setup had some implications for the Andor data, as discussed below. At the time of the observations presented here, Andor was located at the Auroral Station in Adventdalen beside SIF. The imager consisted of an Andor iXon EMCCD detector, running with $2 \times 2$ binning at a time resolution of 2 frames per second. It was fitted with a $50 \mathrm{~mm}$ lense providing a $9^{\circ}$ square field of view and pointed towards the magnetic zenith. Celestial coordinates were established on the image, using the observed positions of known stars from the Smithsonian Astrophysical Observatory (SAO) astronomical star catalogue. A narrow passband interference filter $\left(\lambda_{c}=732.5 \mathrm{~nm}\right.$ and $\left.\mathrm{FWHM}=3 \mathrm{~nm}\right)$

\footnotetext{
${ }^{1}$ Ivchenko, N., Lanchester, B. S., Höök, J., Bampton, M., Dahlgren, H., Whiter, D., Strømme, A., and Ivanov, Y.: Auroral Structure and Kinetics - a new optical instrument for auroral studies, J. Appl. Rem. Sens., submitted, 2008.
} 


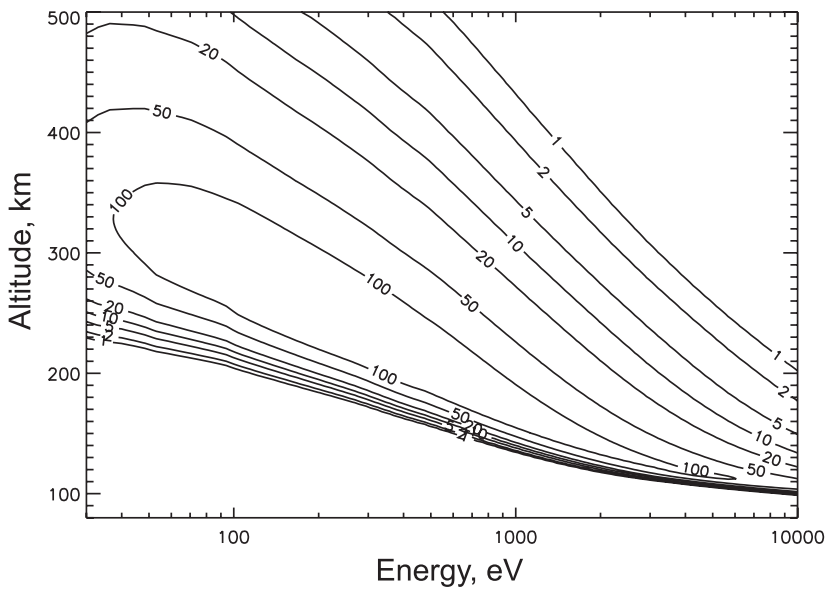

Fig. 1. Modelled (OII) $\left({ }^{2} \mathrm{P}-22 \mathrm{D}\right)$ doublet emission in units of [photons $/ \mathrm{cm}^{3} / \mathrm{s}$ ], as a function of energy and altitude.

was used, centred on the forbidden oxygen (OII) ${ }^{2} \mathrm{P}-{ }^{2} \mathrm{D}$ doublet at $732 \mathrm{~nm}$ and $733 \mathrm{~nm}$. This emission is most effectively excited by low energy $(100 \mathrm{eV})$ electron precipitation, peaking at altitudes of around $300 \mathrm{~km}$. Figure 1 shows the energy and altitude dependence of the forbidden oxygen emission, as modelled using the electron transport model of Lummerzheim and Lilensten (1994).

Emission from the forbidden oxygen doublet is embedded in that from the first positive band of molecular nitrogen $\left(\mathrm{N}_{2}\right.$ 1PG) between 670 and $750 \mathrm{~nm}$ in the auroral spectrum. Figure 2 shows measurements taken with the HiTIES spectrograph covering the wavelength range of the Andor imager. During the initial operations presented here, the mosaic filter containing the forbidden oxygen doublet panel was not in use; the example spectra shown in Fig. 2 are from a later interval. The four different colours show the emission spectra present in four consecutive $30 \mathrm{~s}$ intervals. It can be seen how the differing levels of the oxygen doublet at $732 \mathrm{~nm}$ and $733 \mathrm{~nm}$ and the background nitrogen bands both contribute to the emission within the Andor passband, shown by the black dashed line. This is discussed in detail in Dahlgren et al. (2008b). The contaminant $\left(\mathrm{N}_{2}\right.$ 1PG) emission in the Andor camera is almost independent of characteristic energy, being instead proportional to the total energy flux. This emission is excited at lower altitudes compared with the (OII) emission, with a peak emission altitude at around $110 \mathrm{~km}$.

The existing optical imager on the platform, here termed "SIF", at the same location as Andor, was also used in this study. It was directed towards the magnetic zenith and mapped onto the sky using observed stars from the SAO catalogue. SIF is an intensified CCD imager, with 25 frames per second temporal resolution and a $16^{\circ}$ by $12^{\circ}$ field of view. For this event, SIF was fitted with a long pass RG645 filter with passband $\lambda>645 \mathrm{~nm}$. This was chosen to exclude the long-lived $630 \mathrm{~nm}$ and $557.7 \mathrm{~nm}$ emissions, mak-

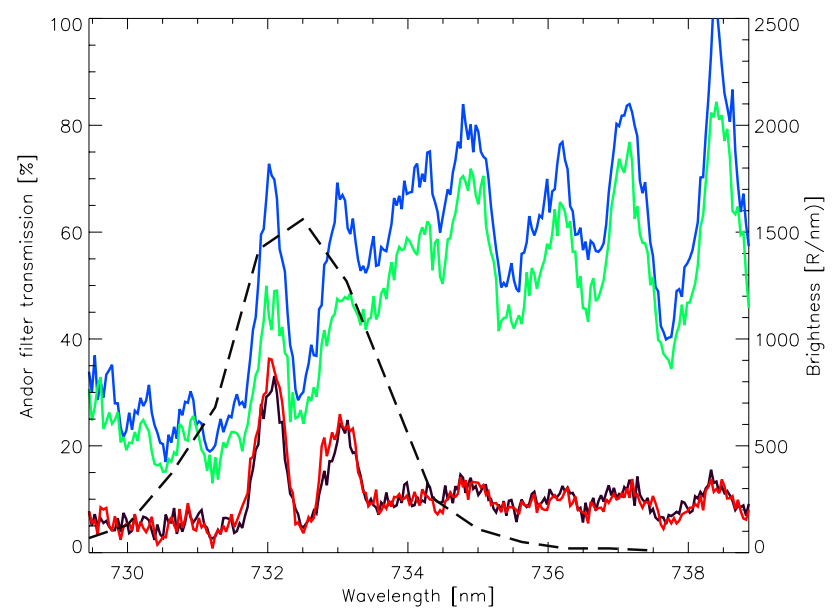

Fig. 2. HiTIES spectrograph plot showing the intensities of auroral emission lines as a function of wavelength. Data from four consecutive $30 \mathrm{~s}$ integrations are shown by (in order) the black, blue, green and red lines. The response of the filter used on the Andor imager is shown by the black dashed curve.

ing this imager primarily sensitive to the $\left(\mathrm{N}_{2} 1 \mathrm{PG}\right)$ and $\left(\mathrm{N}_{2}^{+}\right)$ Meinel emissions in the passband (but also including the (OII) doublet, and a number of atomic oxygen transitions).

Frames from both imagers were flat-fielded and corrected for the dark level. The observations were taken in morning twilight conditions, so the varying contribution to the images due to sunlight was subtracted, along with the instrumental dark-noise level. The sunlight contribution was estimated by a linear fit to brief periods of clear sky before and after the main auroral event in both cameras. Both imagers were intensity calibrated, using stars visible in the clear sky periods used for sunlight subtraction. This star calibration procedure is documented in full in Ivchenko et al. (2008) ${ }^{1}$. Dropouts occurred in the intensity level recorded by the Andor imager at regular intervals, which were caused by overheating (temperature control systems are now employed on the final ASK instrument). Measurements during these periods have been removed, leading to a non-continuous Andor data set. Careful analysis of the remaining data confirms that the gain was uniform and stable.

\section{Observations}

This study concerns the interval from 08:50 UT to 10:00 UT on 22 January 2004, in which multiple NEIAL events were recorded by the ESR. The Svalbard EISCAT Rocket Study of Ion Outflows (SERSIO) sounding rocket was launched just before 09:00 UT. Other publications using the rocket data have described the background conditions and context, which will therefore only be summarized here. Summary plots of the radar data for the overall period, the solar wind 


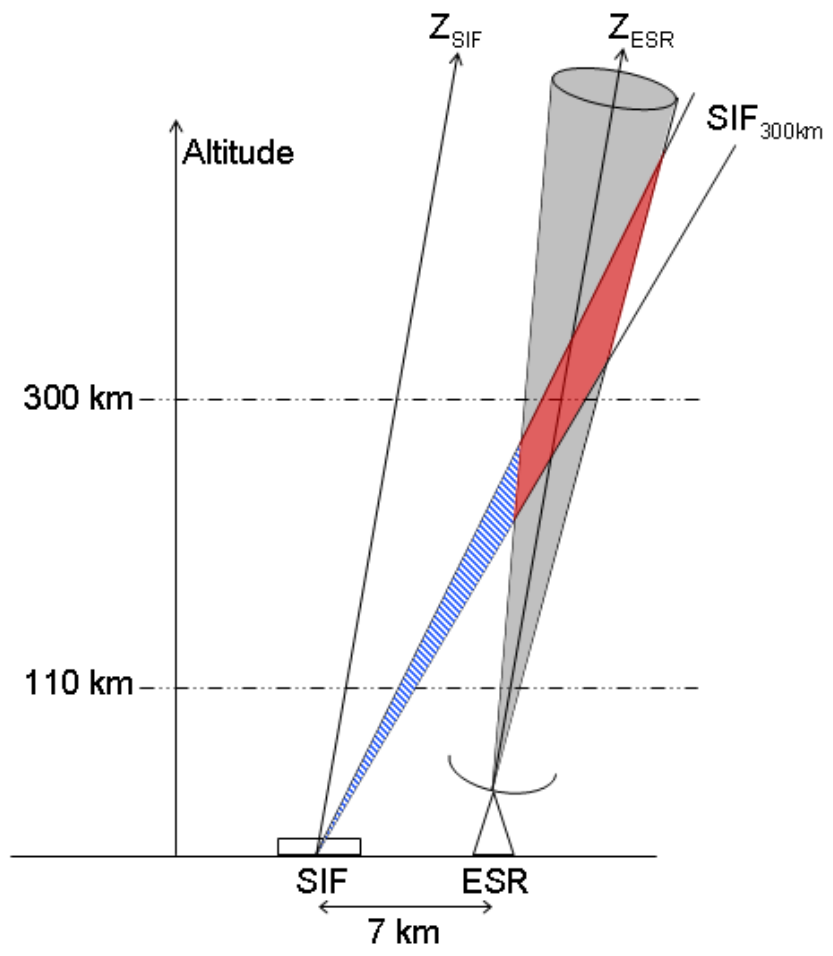

Fig. 3. Representation of the viewing geometry used in this study. The emission volumes observed by the two imagers at the Auroral Station site are compared to the scattering volume illuminated by the ESR beam.

conditions as measured by the Advanced Composition Explorer (ACE) and DMSP data can be found in Lorentzen et al. (2007).

The observations took place during a period of active solar wind conditions measured by the ACE spacecraft, following a coronal mass ejection a few days earlier. The earthward component of the solar wind speed averaged $650 \mathrm{~km} \mathrm{~s}^{-1}$ throughout the interval. A sharp drop in the solar wind density and dynamic pressure occurred at ACE between 08:10 UT and 09:20 UT. Using a calculated 40-min lag time, this corresponds exactly to the interval in which NEIALs are seen in the radar data. The Interplanetary Magnetic Field (IMF) measurements showed a $B_{Z}$ component turning positive at 07:45 UT at the ACE spacecraft, which for the propagation delay estimated here, corresponds to 08:25 UT at the dayside magnetopause. IMF $B_{Z}$ then remained weakly positive until 09:20 UT in ACE measurements, again corresponding to the end of the interval in which NEIALs are seen in the ionosphere. IMF $B_{Y}$ was strongly negative throughout the interval.

Observations from a nearby DMSP satellite pass indicate a lobe reconnection configuration, with an anti-clockwise lobe convection cell over Svalbard. Soft particle precipitation is present throughout the interval, with associated Joule heat- ing and strong pulsed ion upflow in the region of our observations. Data from the Longyearbyen station of the IMAGE magnetometer network (Viljanen and Häkkinen, 1997) show a negative bay in the X-component of magnetic field peaking at 08:45 UT with an amplitude of around $200 \mathrm{nT}$, representing the passage of a large-scale current overhead. The interval studied here takes place during disturbed magnetic activity directly following this feature. Quasi-periodic oscillations, with amplitudes of approximately $50 \mathrm{nT}$, are seen in the IMAGE magnetometer data until 10:00 UT.

This study compares the level of the emissions present in both of the narrow-view imagers with the times of NEIAL power enhancements in the ESR. The time resolution of the radar data available for this study is not high enough to follow the behaviour and evolution of an individual NEIAL, which varies on a sub-second time scale. The collection of raw voltage level data at millisecond resolution was unfortunately not implemented at the radar for this campaign season, but will now be in operation whenever possible for future ESR runs during cusp hours. However, this interval contains an unprecedented number of NEIALs occurring in a relatively short period, which allows us to make a statistical study of the relationship between NEIALs and the aurora present in the radar beam.

\subsection{Optical analysis}

Previous studies have used wide-angle optical instruments to study the auroral precipitation characteristics over Svalbard during times of NEIALs. However, the filamentary NEIALs and the dynamic structured aurora seen to be associated with them are small-scale in nature. This means it is important to use optical measurements of higher spatial resolution. It is also important to use different wavelength emissions in the radar beam to provide information about the precipitating energy spectrum.

\subsubsection{Viewing geometry}

A schematic view of the instrumentation geometry is shown in Fig. 3. At the resolution of sub-kilometer spatial scale, the spatial separation between the imagers and the ESR becomes important; cross sections of the radar beam at different heights map to different locations in the image frames as seen from the Auroral Station. If the Andor and SIF imagers had been co-located with the radar beam, then the intensity recorded would be a combination of oxygen doublet and nitrogen emissions all located within the main beam. The separation of the optical instrumentation and the ESR therefore helps in this respect, in that the two main emissions in the beam are separated by altitude, and are therefore also separated in the images. The area on the Andor images representing the ESR beam at $300 \mathrm{~km}$ will contain only the oxygen contribution of the in-beam emission. The use of observations slightly oblique to the field line, separating 


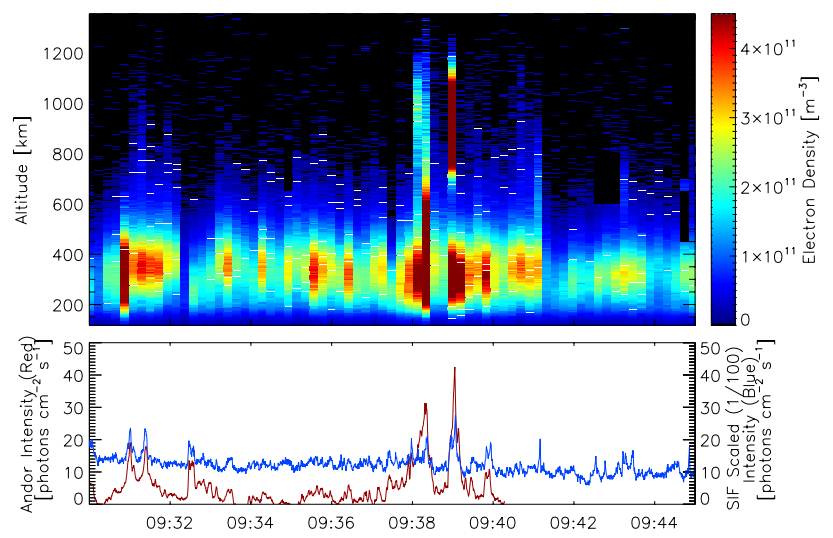

Fig. 4. Data for the interval 09:30-09:45 UT. Top panel: ESR raw electron density (scaled Debye-corrected backscattered power) as a function of altitude and time. Bottom panel: Intensity of the optical emission within the solid angle corresponding to the radar beam at $300 \mathrm{~km}$ altitude for the Andor imager (in red) and the SIF imager (in blue).

emissions by altitude, was shown to be possible by Semeter (2003).

However, the separation causes a new source of the nitrogen contaminant in the Andor imager. Figure 3 shows a representation of the source of this possible contamination, with an exaggerated view of the observation geometry used here. The area on the Andor image representing the position of the ESR beam at $300 \mathrm{~km}$ will mainly consist of the contribution from low-energy emission within the beam, shown by the red shaded region. However there may also be some emission from higher energy precipitation outside the beam at lower altitudes, shaded in blue, contributing to the total line of sight intensity. By comparing the Andor (OII) intensity with the intensity in the wider filter of the SIF imager at the same look direction, this contamination can be quantified.

It can also be seen in Fig. 3 that when observing from a site separated from the radar, aurora from high-energy particles seen in the direction of magnetic zenith, will not be located in the main radar beam, due to the low altitude of emission. Previous studies looking at the relationship between high energy particles and NEIALs have not always accounted for this (Lunde et al., 2007). Since the filaments associated with NEIALs have been shown to have scale sizes much smaller than the width of the radar beam, this is an important consideration.

\subsubsection{Observational results}

From the analysed E-region radar data over the entire interval (not shown here), it is apparent that there is a much larger population of high-energy electrons precipitating at the beginning of the period, associated with the prior interval of southward IMF. As time progresses, the precipitation

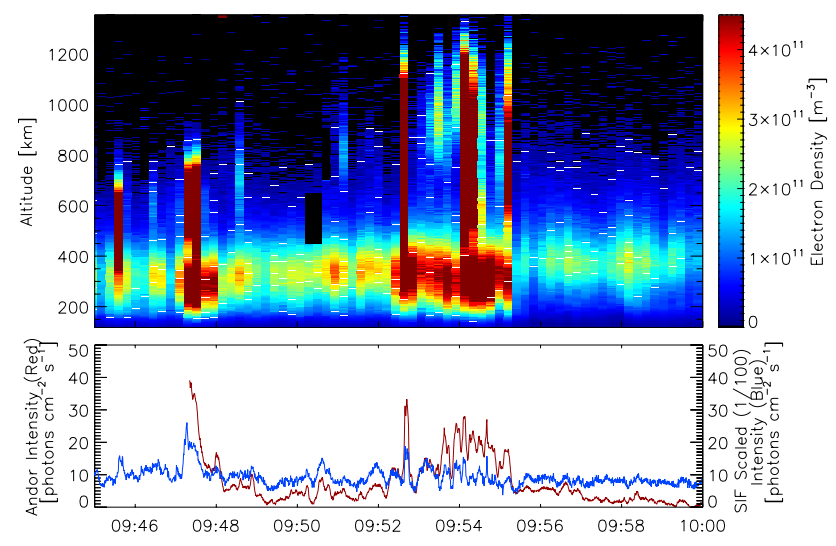

Fig. 5. As Fig. 4, for the interval 09:45-10:00 UT.

becomes more dominated by low-energy precipitation. The implications of this are discussed further in Sect. 5.

The data from 08:45 UT to 10:00 UT have been split into 15 min sections in order to study how the relationship between auroral emission and NEIALs was affected by the varying characteristics of the incoming precipitation. Figures 4 and 5 show the relationship between the enhancements in ESR backscattered power and the intensity of the optical emissions in two consecutive 15 min periods. The top panel shows the temperature-corrected backscattered power from the ESR, scaled to represent units of electron density (applies only for thermal plasma), as a function of altitude on the vertical axis and time on the horizontal axis.

Although the ESR experiment "tau0" does not have a separately recorded power profile in the coding, this plot was made by extracting the zero lag measurements from the second alternating code, which gives a representation of power. However, zero lag values, while giving the best signal-tonoise ratio, are not fully decoded in range, leading to NEIAL features appearing from a larger than true altitude range. Nevertheless, Figs. 4 and 5 are adequate for NEIALs to be identified clearly in the ESR spectra by the increase in scattered power received over an extended altitude range, compared to the normal thermal level. Satellite signals in the data appear as similar enhancements in power, but are only present in a restricted altitude range, i.e. in one or two radar range gates, assuming the data is fully range decoded. Power enhancements due to satellites were identified by looking directly at the range extent in the raw spectra (spectra are composed by combining several short lags and are therefore fully decoded in range) and also by noting visible satellite crossings in the imager frames. Power measurements corresponding to identified satellite enhancements have been reset to zero, and can be seen as black features appearing with an altitude range of about $200 \mathrm{~km}$ (due to the break-down in range decoding) in the profiles. 

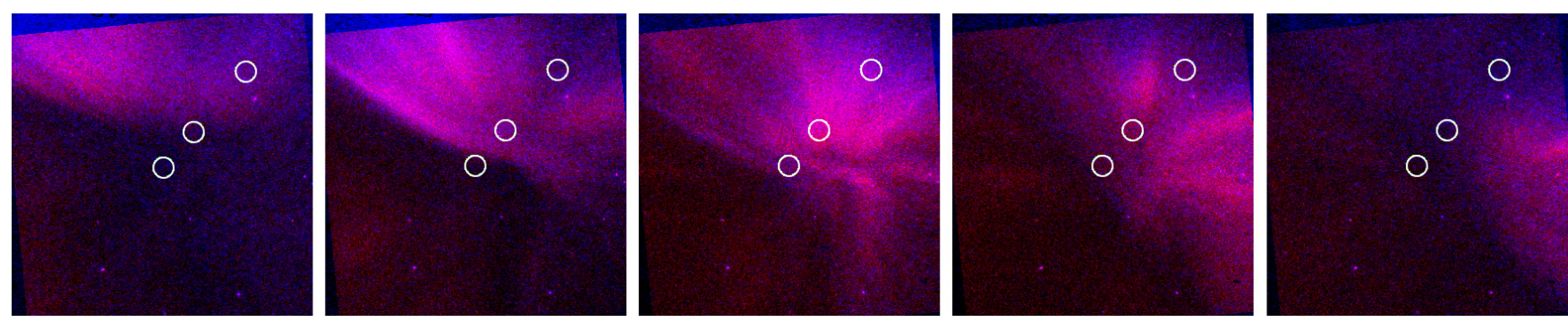

Fig. 6. Multi-wavelength composite image showing the optical (OII) enhancement associated with the NEIAL signature at 09:39:03 UT. The frames shown were taken at 09:38:53, 09:38:58, 09:39:03, 09:39:08 and 09:39:13 UT from left to right. The direction of north is vertically downwards and the east direction is to the left for the image orientation as shown here. The white circles shown progressively further out from the centre of the image, represent the position of the ESR beam (FWHM 0.6 degrees) at altitudes of infinity, $300 \mathrm{~km}$ and $110 \mathrm{~km}$ respectively. The result of not taking into account the parallax effect, i.e. effectively assuming infinite altitude, can clearly be seen.

There is some evidence for enhancements in electron density at or below about $400 \mathrm{~km}$, corresponding to NEIAL events at higher altitudes, for example at 09:39 UT in Fig. 4. In cases where the low-altitude enhancement is separate from the NEIAL at higher altitude, with a clear distinction between maxima as in the example noted, these are likely to be real density enhancements. The radar data alone therefore shows direct evidence for soft electron precipitation accompanying NEIALs, with electrons of $100 \mathrm{eV}$ energy causing an ionisation peak at around $250 \mathrm{~km}$ altitude (modelled using the electron transport model of Lummerzheim and Lilensten, 1994, and shown in Whiter, 2008). However, because of the use of the zero-lag profile and the associated large range ambiguity, care must be taken where there is no clear distinction. There is the possibility of NEIAL enhancements affecting range gates at lower altitudes.

The second panel shows the calibrated intensity from the solid angle corresponding to the cross section of the radar beam at $300 \mathrm{~km}$ on the Andor and SIF images, in red and blue respectively. An ESR beam width (full width at half power) of 0.6 degrees is assumed here. With a much larger filter passband than Andor, the intensity levels in the SIF camera are in general much larger, and have been scaled by a factor of 0.01 in order to show them on the same axis. There is also some slowly varying offset in the SIF intensity, that is predominantly due to continuous emission excited by the high energy precipitation but may also contain some residual continuum and solar scattering background. As discussed in detail above, the Andor imager is predominantly responding to the low energy oxygen doublet (OII) emission, with some contamination from the background nitrogen bands, while the SIF imager is primarily sensitive to the $\left(\mathrm{N}_{2} 1 \mathrm{PG}\right)$ emissions in the passband, with some contamination from (OII) and other nitrogen emission. The relative brightness of (OII) and $\left(\mathrm{N}_{2}\right.$ 1PG) emissions therefore depends on the energy of the precipitating particles.

These time intervals, taken from the end of the period of NEIAL activity, when the emission from high energy pre- cipitation is low, show a clear correlation between discrete NEIALs and times of increased in-beam Andor emission. It can be seen that the main peaks in Andor, corresponding to the times of NEIALs are characterised by an increase in the Andor to SIF ratio, ie. the Andor intensity is predominantly enhanced. This confirms that at these times Andor is responding specifically to an increase in low energy precipitation enhancing the (OII) emission, rather than an increase in the $\left(\mathrm{N}_{2} 1 \mathrm{PG}\right)$ background. The increased Andor to SIF ratio at times of NEIALs therefore implies that the related auroral structures are the direct result of low energy electron fluxes, entering the topside ionosphere i.e. "primary precipitation", and not due to secondaries resulting from successive collisions of higher energy precipitating particles as they pass through the ionosphere.

\subsection{Imaging an individual NEIAL}

Throughout the entire interval of interest, rayed coronal aurora was observed, with a large scale drift northwards across the sky. NEIALs occur at the same time as short-lived auroral structures pass through the radar beam. These have been shown to be predominantly low energy features.

Overlaid images from both Andor and SIF, as shown in Fig. 6, can provide an image of the optical evolution of a NEIAL signature, both spatially and in energy. In the composite images Andor data are shown in red, SIF data in blue. The overlaid frames shown are taken at $5 \mathrm{~s}$ intervals, with the central (third) image at 09:39:03. This corresponds to the discrete NEIAL signature and the related optical intensification at 09:39:03, as shown in Fig. 5.

The three white circles marked on the images represent the position of the radar beam, again using the nominal angular diameter of 0.6 degrees, at different altitudes mapped onto the image coordinate frame. The circle nearest the centre of the image frames shows the position of the ESR if no parallax considerations are taken into account, i.e. assuming the camera and radar are at the same location, effectively 

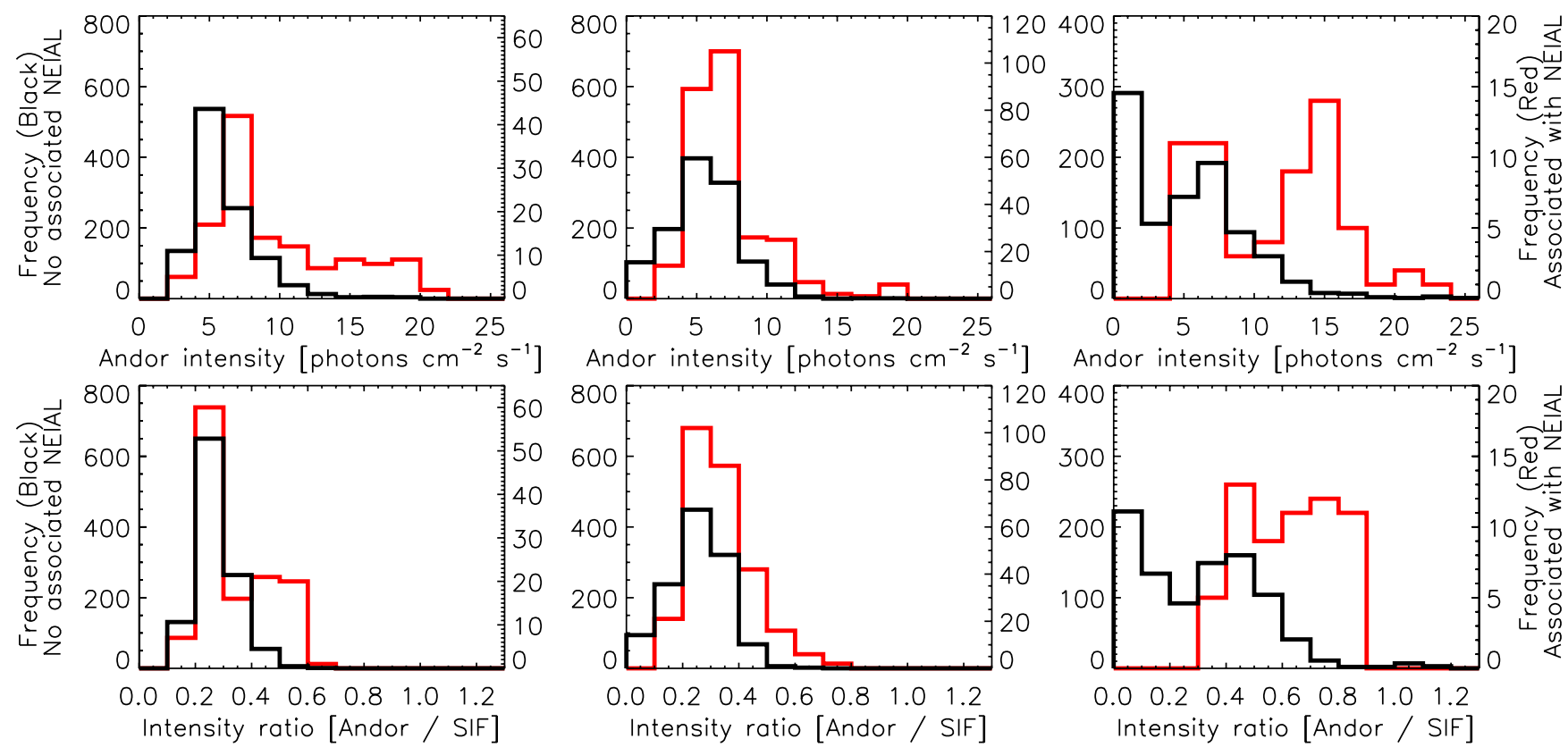

Fig. 7. Andor intensities and Andor/SIF ratios separated into data points associated with a NEIAL (shown in red), and those where no NEIAL was recorded, (shown in black). The histograms shown are for 15 min intervals of data, starting, from left to right at 08:45 UT, 09:00 UT and 09:15 UT, respectively.

mapping the radar beam at an infinite altitude. The circles positioned progressively further away from the centre of the image represent the location of the radar beam at $300 \mathrm{~km}$ and $110 \mathrm{~km}$ respectively, i.e. the peak-emission altitudes for (OII) and $\left(\mathrm{N}_{2}\right.$ 1PG) emission, respectively. It can be seen that the feature responsible for the discrete enhancement in the (OII) emission at $300 \mathrm{~km}$ altitude is a spatial structure, with a rayed arc passing through the ESR beam.

\section{Statistical analysis}

A statistical analysis of the interval 08:45 UT to 10:00 UT was made to compare the incidence of fine scale aurora with NEIAL signatures present in the ESR beam. A sampling length of $15 \mathrm{~min}$ was chosen as optimum for the changing ionospheric conditions.

The Andor imager intensity values were separated according to whether or not they were associated with a NEIAL signature in the radar. This was defined as whether they occurred within a time $(T \pm \tau)$ where $T$ is the time of the nearest recorded NEIAL event in the radar, and $\tau$ is $6.4 \mathrm{~s}$, the temporal uncertainty due to the resolution of the radar data points. NEIAL signatures were identified using the backscattered ESR data integrated over the altitudes between $500 \mathrm{~km}$ and $1200 \mathrm{~km}$, i.e. well above normal F-region ionisation altitudes. Individual features with integrated powers over a chosen threshold criteria well above the background level showed up distinctly, and were classed as NEIAL events. As mentioned previously, power enhancements due to satellites had already been removed from the data set. The time series of auroral intensity from the SIF imager was interpolated to the lower temporal resolution (2 frames per second) of the Andor imager. This allows the calculation of ratios for each time step and therefore separates (OII) emission events from $\left(\mathrm{N}_{2}\right.$ 1PG) contamination features.

Figure 7 shows the resulting histograms for the three consecutive 15 min intervals from 08:45 UT until 09:30 UT, progressing from left to right. The top panels show the intensity values recorded by the Andor camera (again integrated within the beam location at $300 \mathrm{~km}$ as in Figs. 4 and 5), separated into those associated with a NEIAL event (shown in red) and those with no associated NEIAL (shown in black). It can be seen that in the first two time intervals the difference between the two is negligible, but in the third plot, starting at 09:15 UT, the separation between the populations becomes significant, with NEIAL events associated with increased emission in the Andor. This distinction is also seen in the plot of camera ratios (bottom panel) for this time section, confirming that it is increased levels of (OII) emission that are associated with NEIAL signatures.

Figure 8 shows similar histograms for the later intervals starting at 09:30 UT and 09:45 UT (data shown in Sect. 3.1.2), when high energy precipitation present in the ionosphere was at a much lower level. Here, two clear populations are evident, both in the Andor intensity alone and 

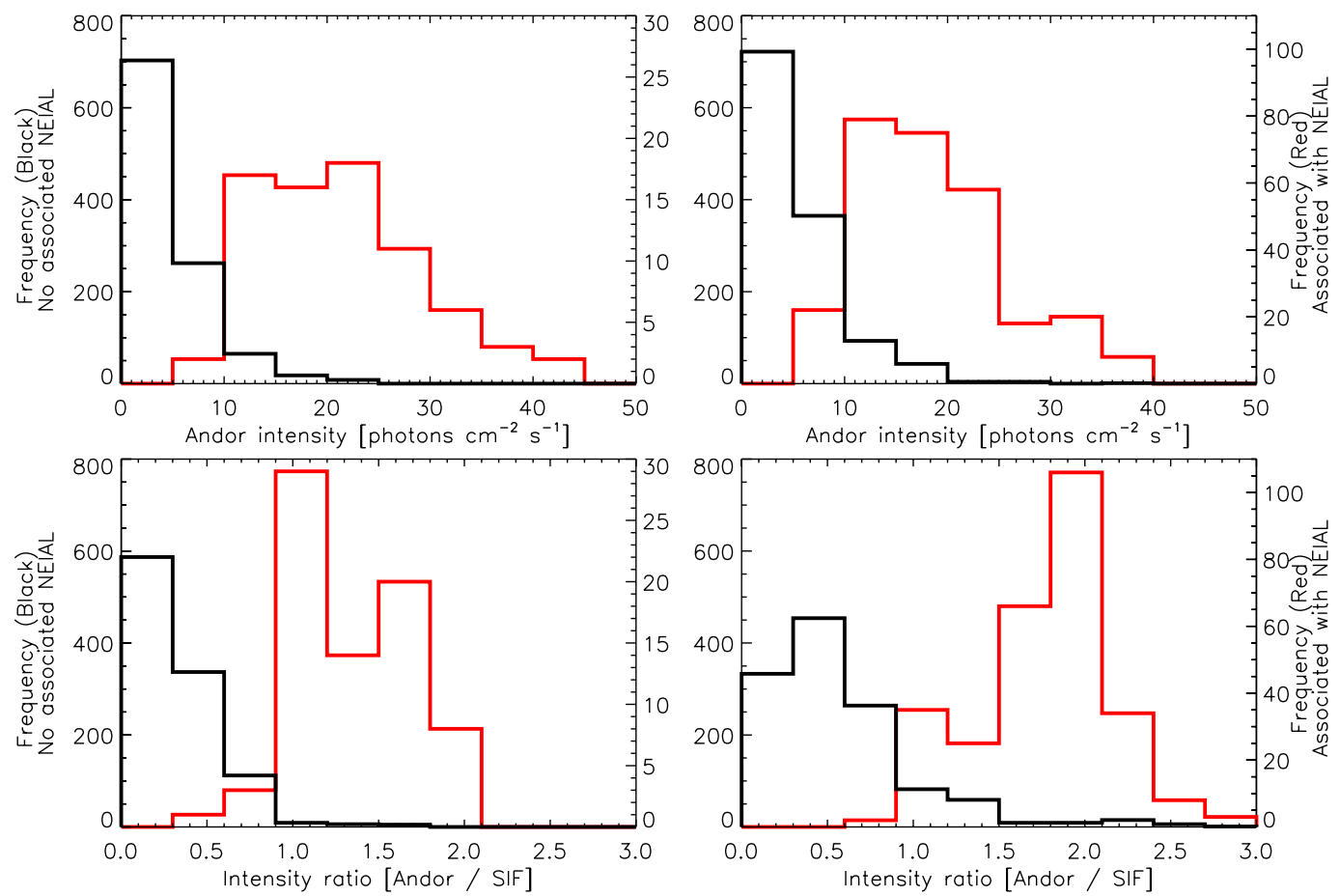

Fig. 8. As Fig. 7 for the 15 min intervals starting at 09:30 UT (left column) and 09:45 UT (right column).

in the Andor/SIF ratio (which may be somewhat affected by the background level in the SIF intensity). Even though the separation is distinct, it is not exclusive, with a third population of precipitation which may or may not cause NEIALs to be generated, i.e. an auroral population near the triggering criteria. This implies that the critical threshold for the generation of NEIALs is not fixed, and may depend on other factors in the ionosphere.

The high occurrence frequencies shown in these histograms reflect, in part, the high temporal resolution of the optical data, in comparison with the integration time for each radar data dump, and also a degree of binning applied to clarify trends. Using the chosen threshold criteria to identify NEIALs, the numbers of affected radar data dumps in each successive $15 \mathrm{~min}$ interval, starting at $08: 45$ UT through to 09:45 UT, are 5, 20, 4, 3 and 13, respectively.

\section{The role of high-energy precipitation}

As shown in Figs. 7 and 8 there is a relationship between times of increased (OII) emission and NEIAL signatures. However, the difference between the population associated with a NEIAL and that which is not, becomes more distinct progressing through the interval 08:45 UT to 10:00 UT, and only becomes significant after 09:15 UT. As mentioned in Sect. 3.1.2, a large population of high-energy particles is present at the start of these observations, which diminishes over time (Fig. 9). An almost unambiguous relationship between NEIALs and auroral intensity is clear when the high energy precipitation is at its lowest. This implies it is the low energy precipitation that is the direct driver for the NEIAL events, and that the relationship between NEIALs and auroral activity becomes harder to discern when the Andor imager is responding more to contaminating emission in the passband from high-energy precipitation. During times of strong $\left(\mathrm{N}_{2}\right.$ 1PG) aurora, the relatively weak contributions from the (OII) doublet to the Andor bandpass are overpowered by the molecular emissions, and become hard to discern. This may explain why there is no significant relationship between the aurora and NEIAL occurrence, even in the ratio plot, for the data between 08:45 UT and 09:15 UT.

Figure 9 shows the radar E-region raw electron densities, representing the effect of ionisation, averaged over each 15 min interval between 08:45 UT and 10:00 UT. Radar data dumps identified as NEIALs have been treated as missing data in the averaging. E-region ionisation is caused directly by the precipitation of high $(>1 \mathrm{keV})$ energy electrons (Rees, 1989). The ionisation profiles therefore clearly show the higher levels of high-energy precipitation at the beginning of the interval, diminishing over time.

These results suggest that the high-energy precipitation from the previous period of negative IMF $B_{z}$, while present to some extent throughout the entire interval, is not related to the NEIALs directly. Instead it appears to mask the true 
link between the aurora and the NEIALs by contaminating the wavelength ranges at which the (OII) emission is present.

\section{Modelling}

An important question to ask in order to justify the interpretation of enhanced ion-acoustic waves driven by decaying electron plasma waves, is whether theoretical models for these processes can replicate the observed events using the ionospheric parameters recorded at the time.

For this study, a pass of the DMSP satellite F-13, at approximately $840 \mathrm{~km}$ altitude, provides a snapshot of the precipitation in the region being sampled by the instruments at Longyearbyen. The DSMP spacecraft measure downward fluxes of ions and electrons, of energies from $30 \mathrm{eV}$ to $30 \mathrm{keV}$ in 19 channels, with a time resolution of one second. The time of closest approach is at 08:44:46 UT, just before the onset of the interval studied here, when the satellite passes within approximately $20 \mathrm{~km}$, and to the north, of the ESR beam.

Figure 10 shows the DMSP F-13 spectrogram for ions and electrons for the interval 08:44 UT to 08:45 UT. Strong bursts of low-energy (around $100 \mathrm{eV}$ ) electrons are observed at 08:44:09, 08:44:14 and 08:44:20 UT. The initial distribution function of energetic electrons, $g(v)=A v^{-\delta}$ was obtained using DMSP F-13 measurements of differential energy flux at 08:44:20 UT, fitted with a power law. The number density of energetic electrons above velocity $v=v_{0}, n\left(v=v_{0}\right)$ is given by $n\left(v=v_{0}\right)=\int_{v=v_{0}}^{\infty} g(v) d v$. The power-law index $\delta \approx 4$ gave a power law fit to the shape of the DMSP spectrum as a whole. This distribution (shown with a dashed line in Fig. 12) was used as one of the inputs to a Langmuir turbulence model, based on that described in Kontar and Pécseli (2002) and Kontar and Pécseli (2005).

The model self-consistently describes the interaction of electrons, Langmuir waves, and ion-acoustic waves in Fregion ionospheric plasma using the approximation of weak turbulence theory. Weak turbulence kinetic equations are solved in time and $\mathrm{k}$-space with time-dependent injection of electrons. Using the assumptions of Kontar and Pécseli (2002), we can write the kinetic equation for the resonant interaction $\omega_{p e}=k v$ of electrons and Langmuir waves (Vedenov et al., 1962).

$$
\frac{\partial f}{\partial t}=\frac{4 \pi^{2} e^{2}}{m^{2}} \frac{\partial}{\partial v} \frac{W_{k}}{v} \frac{\partial f}{\partial v}-\left.v\left(\frac{\partial f_{0}}{\partial x}\right)\right|_{x=x_{S}}(v, t),
$$

where $f(v, t)$ is the electron distribution function, $W_{k}(k, t)$ is the spectral energy density of Langmuir waves playing the same role for waves as the electron distribution function does for particles. The last term introduced in Eq. (1) is a source/sink of electrons mimicking free downward precipitating electrons along the magnetic field lines. The precipitation of electrons is modelled by scatter-free one-dimensional streaming from the satellite location $x=0$ (where electrons

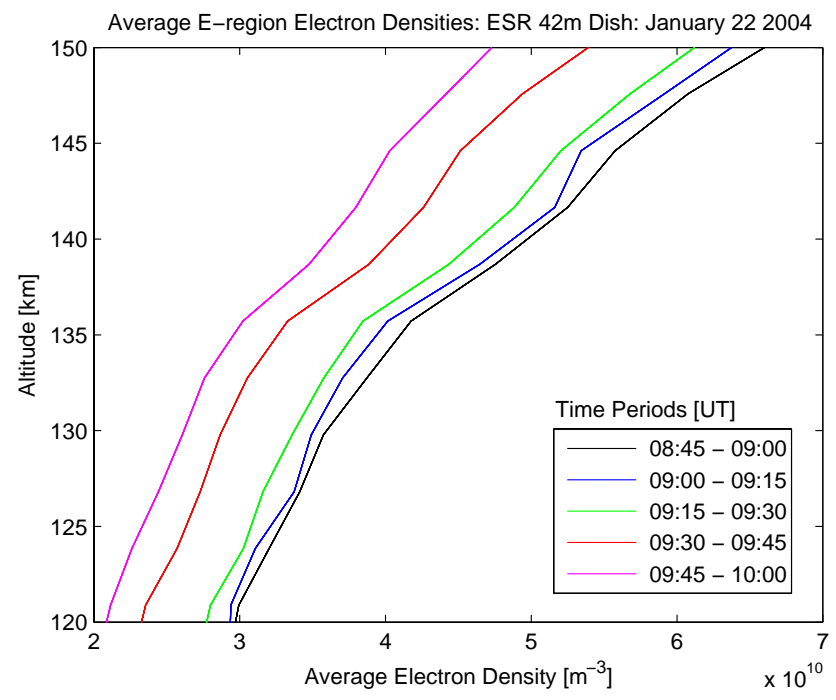

Fig. 9. Average ESR raw electron densities (Debye-corrected) for consecutive $15 \mathrm{~min}$ intervals between 08:45 UT and 10:00 UT.

were measured at approximately $850 \mathrm{~km}$ ) to the depth of the point of simulation $x_{S}=150 \mathrm{~km}$ (the average NEIAL altitude was observed to be around $700 \mathrm{~km}$ ), described by

$f_{0}(v, x, t)=g(v) \exp \left(-(x-v t)^{2} / d^{2}\right)$,

where $d=30 \mathrm{~km}$, and $g(v)=A v^{-\delta}$ is the initial distribution function from satellite data. Equation (1) is solved simultaneously with the corresponding equations for Langmuir waves $W_{k}$

$$
\begin{array}{r}
\frac{\partial W_{k}}{\partial t}=\frac{\pi \omega_{p e}^{3}}{n k^{2}} W_{k} \frac{\partial f}{\partial v}-2 \gamma_{c} W_{k}+S t_{\text {decay }}\left(W_{k}, W_{k}^{s}\right) \\
+S t_{\text {ion }}\left(W_{k}\right),
\end{array}
$$

and ion-acoustic waves $W_{k}^{s}$

$$
\frac{\partial W_{k}^{s}}{\partial t}=-2 \gamma_{k}^{s} W_{k}^{s}+S t_{\text {decay }}\left(W_{k}^{s}, W_{k}\right),
$$

where

$\gamma_{k}^{s}=\sqrt{\frac{\pi}{8}} \omega_{k}^{s}\left[\frac{v_{s}}{v_{T e}}+\left(\frac{\omega_{k}^{s}}{k v_{T i}}\right)^{3} \exp \left[-\left(\frac{\omega_{k}^{s}}{k v_{T i}}\right)^{2}\right]\right]$,

is the Landau damping rate of ion-sound waves, containing both electron and ion components. $v_{s}=\sqrt{\kappa T_{e}\left(1+3 T_{i} / T_{e}\right) / m_{i}}$ is the sound speed. The first term on the right hand side of Eq. (3) accounts for the wave generation/absorption by electrons. The damping term, $\gamma_{c}$, is included to take into account the collisional damping of Langmuir waves with $\gamma_{c}=v_{e i}+v_{e n}, \quad$ where $v_{e i}=\left(34+4.18 \ln \left(T_{e}^{3} / n_{e}\right)\right) n_{e} T_{e}^{-3 / 2}$ and $v_{e n}=5.4 \times 10^{-10} n_{\mathrm{gas}} T_{e}^{1 / 2}$ are electron-ion and electron neutral collisional frequencies respectively. The last two 


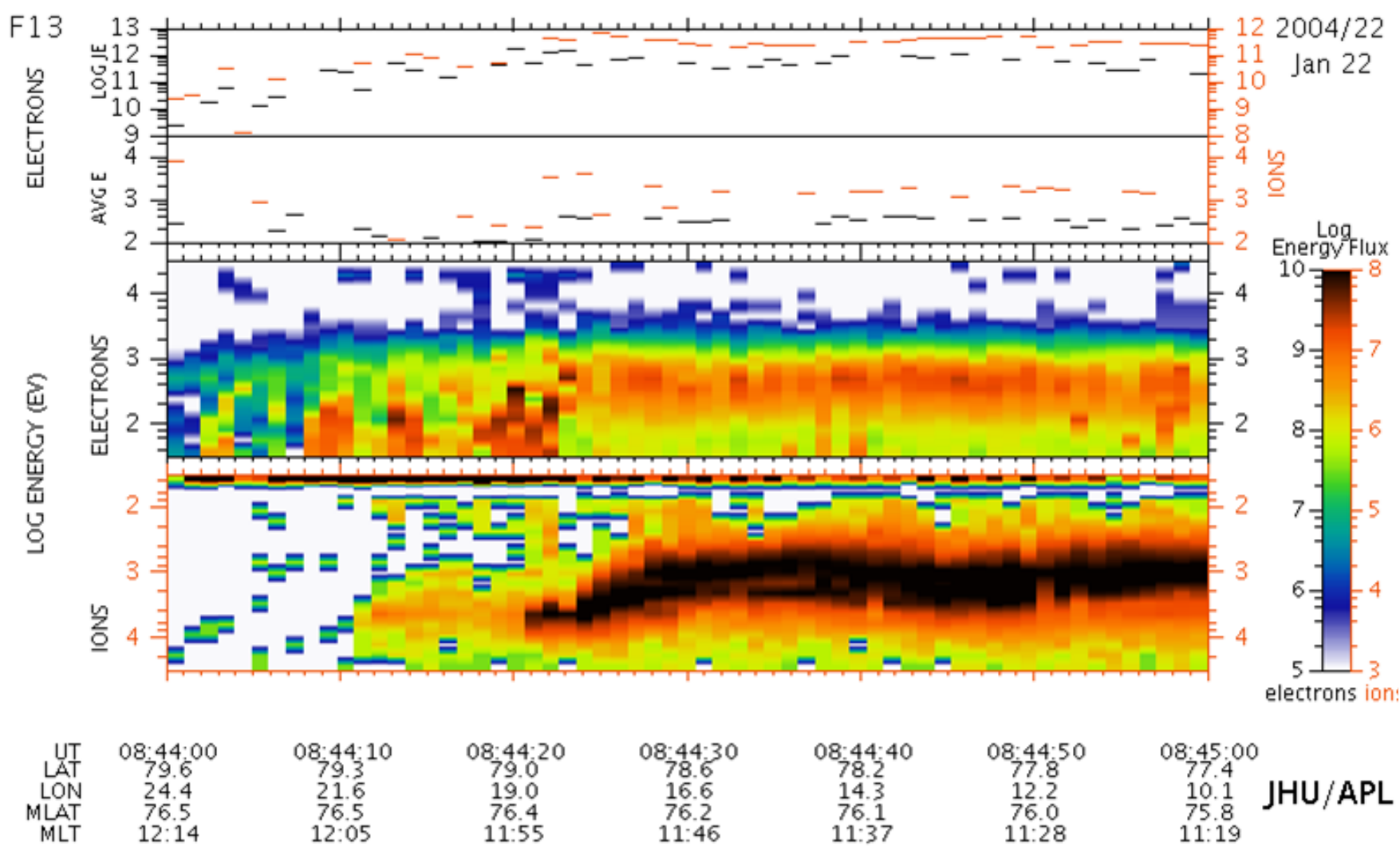

Fig. 10. DMSP spectrogram from the F-13 satellite, for the interval 08:44 UT to 08:45 UT.

Table 1. Plasma parameters for the simulations.

\begin{tabular}{ccccc}
\hline Altitude, $\mathrm{km}$ & $T_{e}, \mathrm{~K}$ & $T_{i}, \mathrm{~K}$ & $f_{p e}, \mathrm{MHz}$ & $n_{\mathrm{gas}}, \mathrm{cm}^{-3}$ \\
\hline 700 & 6000 & 1400 & 2.0 & $5 \times 10^{5}$ \\
\hline
\end{tabular}

terms on the right hand side of Eq. (3) and the last term in Eq. (4) describe nonlinear wave-wave interactions. Specifically, the term, $S t_{\text {decay }}$, describes the decay $L \leftrightarrows L^{\prime}+S$ of a Langmuir wave $\omega_{L}\left(k_{L}\right)$ into a ion-sound wave $\omega_{S}\left(k_{S}\right)$ and a "daughter" Langmuir wave $\omega_{L}^{\prime}\left(k_{L}^{\prime}\right)$, while the term $S t_{\text {ion }}$ denotes Langmuir wave scattering from ions, $L+i \rightarrow L^{\prime}+i^{\prime}$ which is also known as nonlinear Landau damping (see Kontar and Pécseli, 2005, for details). The initial level of Langmuir and ion-sound waves was taken to be thermal $W_{k}(t=0)=W_{T}$ and $W_{k}^{S}(t=0)=W_{T}^{S}$.

As mentioned above, the model was run for an altitude of $700 \mathrm{~km}$, which was found to be the average height of peak power in the raw spectra for all NEIAL data dumps. Background ionospheric parameters were taken from GUISDAP ESR analysis results, at a time resolution of $64 \mathrm{~s}$. Parameter results were integrated between $600 \mathrm{~km}$ and $800 \mathrm{~km}$ to increase signal to noise levels, collected over the interval 08:45 UT to 10:00 UT. Appropriate binning was used to find a clear modal value for electron density, electron temperature and ion temperature. It is important to note that using data from the entire interval means that dumps containing NEIALs, where the analysed values are unreliable, will also be included. However, despite the large numbers of NEIALs in this period, there are still far more thermal dumps than enhanced, leaving the modal value unaffected. Realistic neutral density $n_{\text {gas }}$ values are taken from altitude profiles from the MSIS model. The plasma parameters used in the simulations are given in Table 1.

The evolving electron distribution function $f(v)$ and the spectral energy densities of generated Langmuir $W_{k}$ and ionacoustic $W_{k}^{s}$ waves from our simulations are presented in Figs. 11 and 12. The first non-maxwellian electrons with velocity $v \sim 20 v_{T e}$ appear at the altitude of $700 \mathrm{~km}$ approximately $20 \mathrm{~ms}$ after the start of the simulations (left panel in Fig. 11). After $\sim 25 \mathrm{~ms}$ the number density of fast electrons becomes high enough to generate Langmuir waves (Figs. 11, 12). As a result the electron distribution function starts to relax towards a flatter distribution (red line in Fig. 12). The generation of Langmuir waves continues and the first non-thermal ion-acoustic waves appear at $k \lambda \lambda_{D e} \sim 0.1$ 

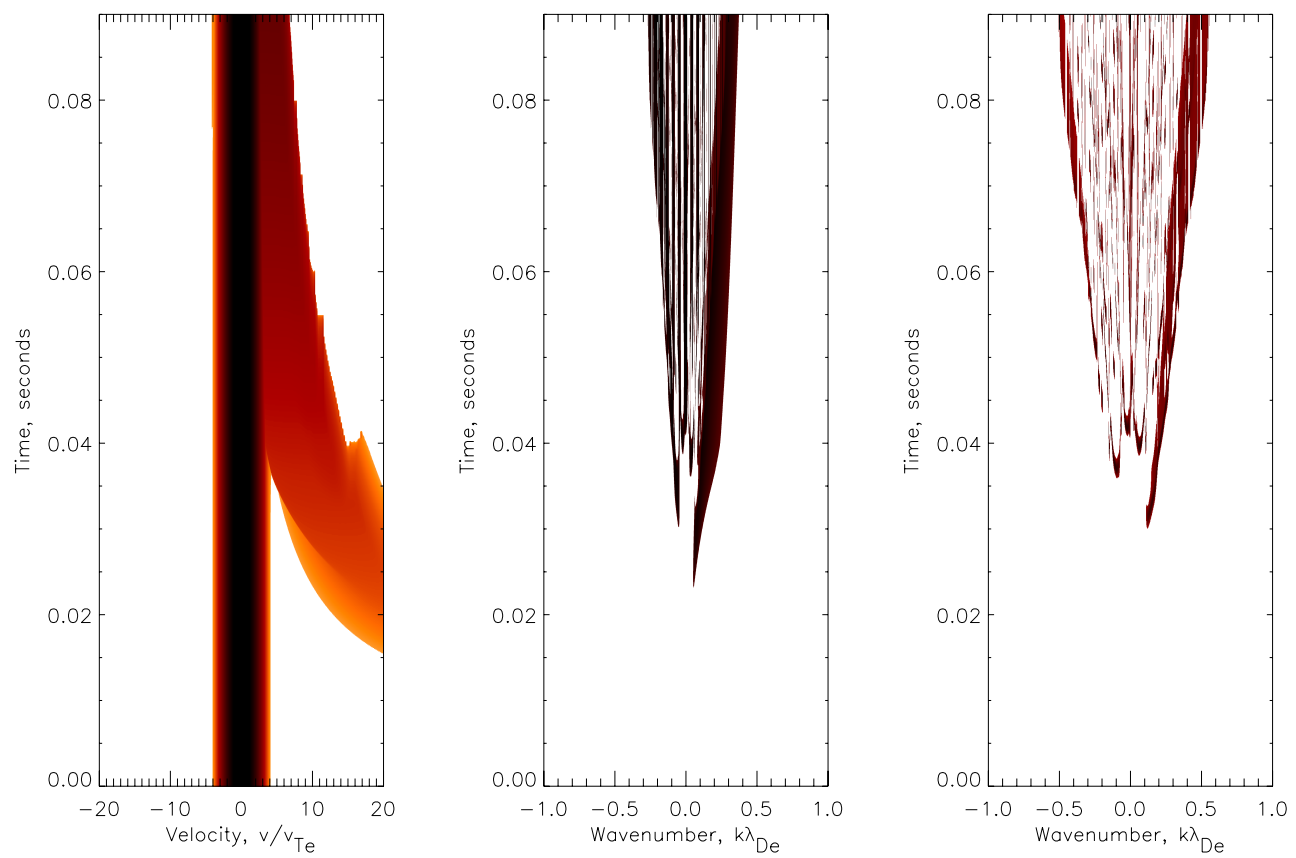

Fig. 11. Evolution of electron distribution function (left panel), Langmuir waves (middle panel) and ion-acoustic waves, (right panel) in time and velocity/wavenumber spaces.

after approximately $30 \mathrm{~ms}$. After this time, Langmuir waves with higher wavenumber $k_{L}$ start to decay and produce ionacoustic waves with larger $k_{S}$. The normalised scattering $\mathrm{k}-$ vector $\left(k_{\mathrm{Bragg}} \lambda_{D e}\right)$ of ion-acoustic waves detected with the ESR is approximately 0.5 , with $\lambda_{D e}=2.4 \mathrm{~cm}$ for the values of electron density and temperature used here. Generated ion-acoustic waves at this k-vector, should be observed as NEIALs in ESR data. The simulation results in Fig. 11 show that the radar should first detect downward propagating (upshifted) ion-acoustic waves approximately $75 \mathrm{~ms}$ after the start of simulations. Upward propagating (downshifted) ionacoustic waves with the same intensity at $k_{\mathrm{Bragg}} \lambda_{D e} \sim-0.5$ only appear later in the simulations at approximately $90 \mathrm{~ms}$ (Fig. 11). The level of ion-acoustic turbulence is around three orders of magnitude above the thermal level, as shown in Fig. 12. It should be noted that Fig. 12 only shows the simulation results up to $35 \mathrm{~ms}$ and does not include the later time steps corresponding to when waves are present at ESR $\mathrm{k}$-vectors. After $40 \mathrm{~ms}$ since the start of simulations, ionacoustic wave activity remains similar in magnitude, with a maximum spectral energy density three orders above the thermal level, seen at $k_{\mathrm{Bragg}} \lambda_{D e} \sim 0.5$ after $80 \mathrm{~ms}$. However at these later times wave activity becomes present at a large range of discrete k-vectors, completely swamping the earlier features. Time steps later than $35 \mathrm{~ms}$ have therefore been omitted from this figure, so that the temporal evolution of the wave growth can still be seen.

\section{Discussion and conclusions}

In this paper, a clear link has been shown between NEIALs in the dayside cusp and emission from low-energy ( $100 \mathrm{eV}$ or less) electrons, using auroral imaging in the forbidden (OII) emission doublet. The results from cameras at two different wavelengths imply that this emission is due to low energy primary electron precipitation, and not secondaries linked to incoming particles of higher energy. Incoming bursts of such electrons, "supra-thermal electron bursts" have been shown to be related to dispersive Alfvén wave activity and acceleration processes (Chaston et al., 2007). One NEIAL event shown in detail here reveals the drift of a small long-lived feature (seen in the imager field of view for over $20 \mathrm{~s}$ ), briefly intersecting the radar beam. This is interpreted as the NEIAL being a spatially distinct feature, as opposed to a purely temporal change within the radar scattering volume. The results here suggest that filaments associated with ion-acoustic enhancements can be persistent within a larger region of precipitation, and are only detected as they pass through the main radar beam.

Using theoretical modelling, the soft precipitation spectrum present at the time of these observations, as recorded by a DMSP pass at $850 \mathrm{~km}$ altitude, has been shown to be sufficient to drive the generation of NEIALs through the mechanism of parametric decay of Langmuir waves. Simulation results reveal the generation of ion-acoustic wave activity at ESR wavelengths, first in the upshifted line and then in the downshifted line, three orders of magnitude above the 

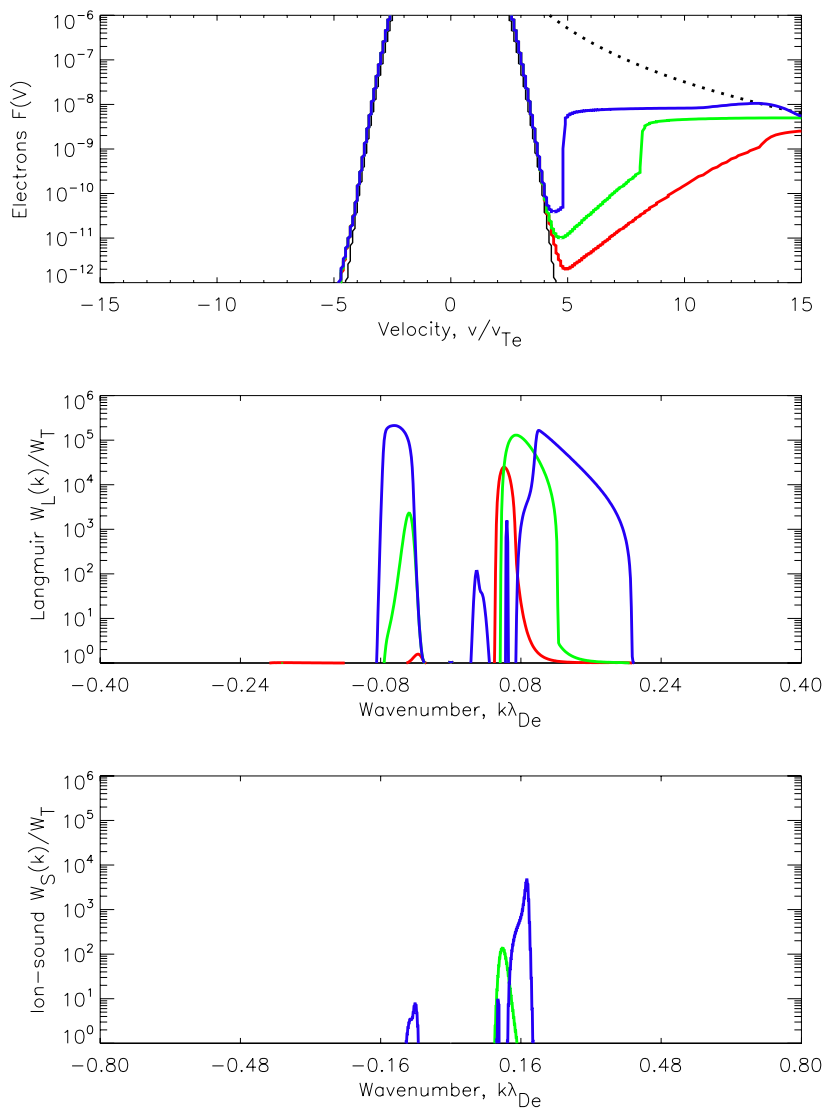

Fig. 12. Electron distribution function $f(v)\left[\mathrm{cm}^{-4} \mathrm{~s}\right]$, Langmuir waves, $W_{k}(k) / W_{T}$, and ion-acoustic waves, $W_{k}^{s} / W_{T}^{s}$ for the plasma parameters at $700 \mathrm{~km}$ at 25,30 , and $35 \mathrm{~ms}$ (red, green, and blue lines, respectively). The dotted line in the electron distribution panel gives the initial electron distribution $g_{0}(v)$ (the power-law fit to the satellite data at 08:44:20 UT).

thermal level. The ability to drive the model using the observed spectrum of precipitation at NEIAL altitudes, as well as observing the effects in terms of auroral emissions lower down in the ionosphere, is of great importance in understanding NEIALs.

High-energy particle precipitation is present to some extent throughout the period in which NEIAL signatures are observed by the ESR. However, statistical analysis indicates that energetic precipitation is not directly linked to NEIAL occurrence. In this case it is masking the relationship with lower energy precipitation. NEIALs in the dayside cusp region are predominantly recorded during times of dynamic rayed aurora (Blixt et al., 2005), and are not observed at times of low-energy quiet arcs which have no high energy component. This suggests that the presence of some energetic particles is favourable for NEIALs to be seen in ESR data.

One possible explanation for this is that a broad mix of precipitating electron energies, i.e. such that has been shown to be present in dynamic rayed auroral forms, has a larger spread of electron beam velocities than a purely low energy population. Using the "parametric decay" interpretation, this therefore increases the bandwidth of the unstable electron population causing the growth of Langmuir waves, which directly increases the range of wavelengths over which ionacoustic waves are enhanced (Forme, 1999). A wider range of precipitating energies therefore increases the chance of enhancement at the fixed wavelength of an IS radar. A greater beam energy spread also increases the chance of satisfying the Bragg conditions for enhanced downshifted and the upshifted line to be observed simultaneously. The vast majority of raw spectra identified as NEIALs in this study show clear enhancements in both lines, although with the time resolution available in this experiment, temporal averaging cannot be ruled out.

Another effect of energetic precipitation may be its role in enhancing the electron temperature in the surrounding ionosphere. From the summary plot showing the analysed radar parameters (shown in Lorentzen et al., 2007), it can be seen that this interval of NEIAL activity is associated with strongly elevated electron temperatures compared to ion temperatures, a feature common in previous NEIAL studies. A higher ratio of electron temperature to ion temperature, as well as increasing the bandwidth of ion-acoustic enhancements, reduces the Landau damping of ion-acoustic waves. The criteria for instability is that the generation of ion-acoustic waves should be faster than their absorption, which is only possible where $T_{e} \gg T_{i}$. This is consistent with studies that have shown the occurrence of NEIALs to be rarer during times of high ion temperature (Ogawa et al., 2006).

In a subsequent paper, we will look in detail at the finescale structure and motions of the precipitation we have shown here to be linked to NEIAL generation.

Acknowledgements. We thank Ian McCrea and Ivan Finch at the EISCAT Support Group, Rutherford Appleton Laboratory for valuable discussions and help with processing the ESR data, and Geoff Daniell for help with the statistical analysis. We also thank the January 2004 EISCAT and optical campaign teams and Andor Inc. for providing the iXon detector on loan. EISCAT is an International Association supported by China (CRIRP), Finland (SA), France (CNRS), Germany (DFG), Japan (NIPR and STEL, Nagoya), Norway (NFR), Sweden (VR) and the United Kingdom (STFC). E. P. Kontar acknowledges the financial support of an STFC Advanced Fellowship. N. Ivchenko is supported by a grant from the Swedish Research Council (VR). The DMSP particle detectors were designed by Dave Hardy of AFRL, and data obtained from JHU/APL. We thank Dave Hardy, Fred Rich, and Patrick Newell for its use.

Topical Editor K. Kauristie thanks M. Rietveld and another anonymous referee for their help in evaluating this paper.

\section{References}

Blixt, E. M., Grydeland, T., Ivchenko, N., Hagfors, T., La Hoz, C., Lanchester, B. S., Løvhaug, U. P., and Trondsen, T. S.: Dynamic 
rayed aurora and enhanced ion-acoustic radar echoes, Ann. Geophys., 23, 3-11, 2005, http://www.ann-geophys.net/23/3/2005/.

Buchert, S. C., van Eyken, A. P., Ogawa, T., and Watanabe, S.: Naturally enhanced ion-acoustic lines seen with the EISCAT Svalbard Radar, Adv. Space Res., 23, 1699-1704, doi: 10.1016/S0273-1177(99)00382-8, 1999.

Chaston, C. C., Carlson, C. W., McFadden, J. P., Ergun, R. E., and Strangeway, R. J.: How important are dispersive Alfvén waves for auroral particle acceleration?, Geophys. Res. Lett., 34, 7101, doi:10.1029/2006GL029144, 2007.

Collis, P. N., Häggström, I., Kaila, K., and Rietveld, M. T.: EISCAT radar observations of enhanced incoherent scatter spectra; their relation to red aurora and field-aligned currents, Geophys. Res. Lett., 18, 1031-1034, 1991.

Dahlgren, H., Ivchenko, N., Sullivan, J., Lanchester, B., Marklund, G., and Whiter, D.: Morphology and dynamics of aurora at fine scale: first results from the ASK instrument, Ann. Geophys., 26, 1041-1048, 2008a, http://www.ann-geophys.net/26/1041/2008/.

Dahlgren, H., Ivchenko, N., Sullivan, J., Lanchester, B. S., Whiter, D., Marklund, G., and Strømme, A.: Using spectral characteristics to interpret auroral imaging in the $732.0 \mathrm{~nm} \mathrm{O+}$ line, Ann. Geophys., 26, 1905-1917, 2008b, http://www.anngeophys.net/26/1905/2008/.

Forme, F. R. E.: A new interpretation on the origin of enhanced ion acoustic fluctuations in the upper ionosphere, Geophys. Res. Lett., 20, 2347-2350, 1993.

Forme, F. R. E.: Parametric decay of beam-driven Langmuir wave and enhanced ion-acoustic fluctuations in the ionosphere: a weak turbulence approach, Ann. Geophys., 17, 1172-1181, 1999, http://www.ann-geophys.net/17/1172/1999/.

Foster, J. C., del Pozo, C., Groves, K., and St. Maurice, J.-P.: Radar observations of the onset of current driven instabilities in the topside ionosphere, Geophys. Res. Lett., 15, 160-163, 1988.

Grydeland, T., La Hoz, C., Hagfors, T., Blixt, E. M., Saito, S., Strømme, A., and Brekke, A.: Interferometric observations of filamentary structures associated with plasma instability in the auroral ionosphere, Geophys. Res. Lett., 30, 1338, doi:10.1029/ 2002GL016362, 2003.

Grydeland, T., Blixt, E. M., Løvhaug, U. P., Hagfors, T., La Hoz, C., and Trondsen, T. S.: Interferometric radar observations of filamented structures due to plasma instabilities and their relation to dynamic auroral rays, Ann. Geophys., 22, 1115-1132, 2004, http://www.ann-geophys.net/22/1115/2004/.

Ivchenko, N., Blixt, E. M., and Lanchester, B. S.: Multispectral observations of auroral rays and curls, Geophys. Res. Lett., 32, 18 106, doi:10.1029/2005GL022650, 2005.

Kontar, E. P. and Pécseli, H. L.: Nonlinear development of electronbeam-driven weak turbulence in an inhomogeneous plasma, Phys. Rev. E, 65, 066 408, doi:10.1103/PhysRevE.65.066408, 2002.

Kontar, E. P. and Pécseli, H. L.: Nonlinear wave interactions as a model for naturally enhanced ion acoustic lines in the ionosphere, Geophys. Res. Lett., 32, 5110, doi:10.1029/ 2004GL022182, 2005.

Lorentzen, D. A., Kintner, P. M., Moen, J., Sigernes, F., Oksavik, K., Ogawa, Y., and Holmes, J.: Pulsating dayside aurora in relation to ion upflow events during a northward interplanetary magnetic field (IMF) dominated by a strongly negative IMF $\mathrm{B}_{Y}$, J. Geophys. Res. (Space Physics), 112, 3301, doi:
10.1029/2006JA011757, 2007.

Lummerzheim, D. and Lilensten, J.: Electron transport and energy degradation in the ionosphere: evaluation of the numerical solution, comparison with laboratory experiments, auroral observations, Ann. Geophys., 12, 1039-1051, 1994, http://www.ann-geophys.net/12/1039/1994/.

Lunde, J., Gustavsson, B., Løvhaug, U. P., Lorentzen, D. A., and Ogawa, Y.: Particle precipitations during NEIAL events: simultaneous ground based observations at Svalbard, Ann. Geophys., 25, 1323-1336, 2007, http://www.ann-geophys.net/25/1323/2007/.

Michell, R.: Examining auroral downward current region processes using ground based data, $\mathrm{PhD}$ thesis, Dartmouth College, Hanover, New Hampshire, 2007.

Ogawa, Y., Buchert, S. C., Fujii, R., Nozawa, S., and Forme, F. Naturally enhanced ion-acoustic lines at high altitudes, Ann. Geophys., 24, 3351-3364, 2006, http://www.ann-geophys.net/24/3351/2006/.

Rees, M. H.: Physics and chemistry of the upper atmosphere, Cambridge atmospheric and space science series, Cambridge University Press, Cambridge, 1989.

Rietveld, M. T., Collis, P. N., and St.-Maurice, J.-P.: Naturally Enhanced Ion Acoustic Waves in the Auroral Ionosphere Observed With the EISCAT 933-MHz Radar, J. Geophys. Res., 96, $19291-$ 19305, 1991.

Rietveld, M. T., Collis, P. N., van Eyken, A. P., and Løvhaug, U. P.: Coherent echoes during EISCAT UHF Common Programmes, J. Atmos. Terr. Phys., 58, 161-174, doi:10.1016/0021-9169(95) 00027-5, 1996.

Rietveld, M. T., Isham, B., Grydeland, T., La Hoz, C., Leyser, T. B., Honary, F., Ueda, H., Kosch, M., and Hagfors, T.: HF-pump induced parametric instabilities in the auroral E-region, Adv. Space Res., 29, 1363-1368, doi:10.1016/S0273-1177(02)001862, 2002.

Sedgemore-Schulthess, K. J. F. and St.-Maurice, J.-P.: Naturally enhanced ion-acoustic spectra and their interpretation, Surv. Geophys., 22, 55-92, doi:10.1023/A:1010691026863, 2001

Semeter, J.: Critical comparison of OII $(732-733 \mathrm{~nm}), \mathrm{OI}(630 \mathrm{~nm})$, and N2(1PG) emissions in auroral rays, Geophys. Res. Lett., 35, 1225, doi:10.1029/2002GL015828, 2003.

Strømme, A., Belyey, V., Grydeland, T., La Hoz, C., Løvhaug, U. P., and Isham, B.: Evidence of naturally occurring wave-wave interactions in the polar ionosphere and its relation to naturally enhanced ion acoustic lines, Geophys. Res. Lett., 35, L05103, doi:10.1029/2004GL020239, 2005.

Vedenov, A. A., Velikhov, E. P., and Sagdeev, R. Z.: Quasi-linear theory of plasma oscillations, Nuclear Fusion Supplement, Part 2., 465-475, 1962.

Viljanen, A. and Häkkinen, L.: Image Magnetometer Network, in: Satellite-Ground Based Coordination Sourcebook, edited by: Lockwood, M., Wild, M. N., and Opgenoorth, H. J., vol. 1198 of ESA Special Publication, pp. 111-118, 1997.

Wahlund, J.-E., Forme, F. R. E., Opgenoorth, H. J., Persson, M. A. L., Mishin, E. V., and Volokitin, A. S.: Scattering of electromagnetic waves from a plasma: enhanced ion acoustic fluctuations due to ion-ion two-stream instabilities, Geophys. Res. Lett., 19, 1919-1922, 1992.

Whiter, D.: A study of auroral fine structure in the magnetic zenith, MPhil thesis, University of Southampton, 2008. 